\title{
CLINICAL EVALUATION OF OSCILLATION METHOD FOR APPLICATION OF A PACKABLE COMPOSITE RESIN
}

\author{
Rania R. Afifi ${ }^{1} M S c$, Ibrahim L. El- Gayar ${ }^{2} P h D$, Wegdan M. Abdel-Fattah'2$P h D$, \\ Fayza Al Abbassy ${ }^{3} P h D$, Amal E. Fahmy ${ }^{3} P h D$
}

\begin{abstract}
INTRODUCTION: Despite all improvements in dental composites, marginal microleakage is one of the most common causes of resincomposite restoration failure. In order to address this concern, efforts have been focusing on dealing with different aspects of composite consistency, polymerization stresses and packing techniques.

OBJECTIVES: The aim of this work is to clinically evaluate the effect of two oscillating packing instruments (ET3000 \& Compothixo) on improving the outcome and the longevity of Quixfil dental packable composite in the everyday practice of general practitioners without the need for placing flowable composite underneath it.

MATERIALS AND METHODS Twenty patients were selected according to specific inclusion and exclusion criteria to participate in this study. Each patient received three posterior class II cavities preparations. The cavities were divided into three groups ( $\mathrm{n}=20$ each) according to the method of composite packing. Test Group I: Quixfil packable composite packed with ET3000, Test Group II: Quixfil packable composite packed with Compothixo \& Group III (Control): incremental placement of Quixfll composite. The twenty patients were followed up for one and a half years according to modified RYGE Criteria. All the data obtained were then statistically analyzed using Friedman test at significance level $5 \%(\mathrm{P}<0.05)$.

RESULTS: All restorations evaluated in this study demonstrated acceptable clinical performance within the evaluation period based on the Alfa and Bravo ratings for clinically satisfactory restorations. Statistical analysis detected no significant differences between the packing techniques.

CONCLUSIONS: Good clinical results can be achieved with oscillation packing techniques when using QuiXfil packable posterior composite.

KEYWORDS: QuiXfil packable composite, oscillation, ET3000, Compothixo.
\end{abstract}

1- Assistant Lecture of Operative Dentistry, Conservative Dentistry Department, Faculty of Dentistry, Alexandria University, Alexandria, Egypt.

2- Professor of Conservative Dentistry, Faculty of Dentistry, Alexandria University, Alexandria, Egypt.

3- Professor of Dental Biomaterials, Faculty of Dentistry, Alexandria University, Alexandria, Egypt.

Corresponding author:

E-mail: rania3afifi@gmail.com

\section{INTRODUCTION}

Dentists expect from modern technology a composite material with high esthetic value, less polymerization shrinkage, perfect marginal integrity, acceptable physicomechanical properties, ease and short time of placement (1).

Many dentists find the incremental placement technique of composite resin quite tedious and very time consuming (2). The concept of "bulk fill" to reduce the time necessary to place and adapt multiple layers of composite resin has been appealing to dentists for some time. In fact, dentists indicated they would choose a technique for posterior restorations using a bulk fill over a technique where the composite is layered (3).

The concern regarding bulk fill restorations, and the reasons why they haven't become standard technique, has been centered on adaptation to cavity walls, depth of cure and volumetric shrinkage (4).

Polymerization shrinkage results in volumetric contraction, causing stresses in bonded restorations that can lead to deformation of the cusps, microleakage, decrease of marginal adaptation, enamel microcracks and postoperative sensitivity (5).
Layering technique (or stratification) is a method of composite placement that addresses that deals with microleakage and shrinkage of the composite filling issue (6). "Polymerization shrinkage is reduced through the insertion of increments in such a way to decrease the configuration factor (C-Factor)" (7).

Packable composites, sometimes also called condensable composites, have been introduced to the market with high expectations as an alternative to amalgam (resin-based amalgam substitute). They are used in stress bearing posterior restorations with improved handling properties, as an application technique similar to the manipulation of amalgam can be used for the placement (8).

Easier establishment of physiological interproximal contacts in Class II restorations, the use of metal matrix bands and wooden wedges, and possible bulk curing of the restorations are advantageous. These clinical advantages of packable composite resins captured the interest of clinicians. On the basis of the perceived high-filler load, these materials were expected to exhibit superior physical and mechanical properties besides the improvements in handling (9). 
A newly invented technique was introduced during the past years to temporary enhance the flowability and handling of packable composites during placement inside the cavity. This procedure utilizes specific oscillating action, after which the composite returns to its hard consistency to withstand the future applied forces on it. Thereby the need for flowable composite placement underneath the restoration is eliminated. $(10,11)$. This oscillating composite placement is based on the highspeed, definite back-and-forth action to the composite material that immediately reduces its viscosity, allowing it to flow much more freely (1).

Also, because the oscillating placement blade strikes the material and withdraws so quickly, the material does not have time to adhere to the placement blade and therefore does not stick, thus pull-back is eliminated (12).

Thus, a condensable material with increased viscosity can be used similar to a flowable composite, without the disadvantage of high polymerization shrinkage and poor mechanical properties (13).

Studies assessed the vibration technique are scares, also little information is offered by the producers of such devices being available. In fact, SonicFill (Kerr Corp, USA/KaVo, Germany) is widely used nowadays and the difference between this system and the technique applied in this study is that, SonicFill uses a specially designed hand piece and composite material in unidose tips. Thus it cannot be applied to any packable composite (14).

In light of the mentioned information, further research was needed to assess the efficacy of using two different oscillation packing method for composite placement on improving the outcome and the longevity of packable dental composites in the everyday practice of general practitioners in comparison with the traditional incremental technique. Therefore, the null hypothesis of this study was, that there will be no difference in the clinical behavior of the packable composite resin after using the oscillation packing method.

\section{AIM OF THE STUDY}

This study aimed to clinically evaluate the oscillation packing methods for application of packable composite resin.

\section{MATERIALS AND METHODS}

This study was carried out as a randomized controlled clinical trial design. Twenty patients were selected from the outpatient clinics of the Conservative Dentistry Department, Faculty of Dentistry, Alexandria University. The selection of the patients was performed according to the following criteria.

Inclusion criteria (15)

1.Patients having posterior class II carious lesions were included.

2. Patients of ages ranging from 20 to 40 years.

3. Absence of pain from the tooth to be restored.

4. Good oral hygiene maintenance.

5. Absence of any active periodontal and pulpal disease.

Exclusion criteria (16)

1. Patient's teeth having deep carious lesions.

2. Patients with pre-procedure sensitivity.

3. Patients with bruxism habits.

4. Patients with known allergic reactions against any materials to be used.
This clinical study was performed after the approval of research ethics committee, Faculty of Dentistry, Alexandria University. Official consent was obtained from the patients. The patients received both oral and written information about the study protocol and signed their informed consent for agreeing to participate in the study.

The current study was conducted using the nanohybrid packable posterior composite Quixfil, which was packed with ET3000 and Compothixo composite packing instruments. Product information, material composition and manufacturers are shown in table 1.

Table (1): The materials and instruments used in the study, their composition /specifications and manufacturer.

\begin{tabular}{|c|c|c|}
\hline Material & Composition & Manufacturer \\
\hline $\begin{array}{l}\text { Nanohybrid packable } \\
\text { postcrior compositc } \\
\text { (QuiXfill) }\end{array}$ & $\begin{array}{c}86 \% \text { by weight } \\
\text { (66\%volume)filler load } \\
\text { UDMA, TEGDMA, di-and } \\
\text { trimethacrylate resins, } \\
\text { carboxylic acid-modified } \\
\text { dimethacrylate resin, BHT, } \\
\text { UV stabilizer, } \\
\text { camphorquinone ethyl-4- } \\
\text { dimcthylaminobenzoate, } \\
\text { silinated strontium } \\
\text { aluminum sodium fluoride } \\
\text { phosphate silcate glass }\end{array}$ & $\begin{array}{c}\text { Dentsply/Caulk, Milford, } \\
\text { DE, USA }\end{array}$ \\
\hline $\begin{array}{c}\wedge \text { cid etch } \\
\text { Conditioner } 36^{\text {ie }}\end{array}$ & $36 \%$ phosphoric acid gel & $\begin{array}{c}\text { Dentsply/Caulk, Milford, } \\
\text { DE, US } \Lambda\end{array}$ \\
\hline $\begin{array}{c}\text { Bonding agent } \\
\text { Prime \& Bond } \mathrm{NT}^{*}\end{array}$ & $\begin{array}{l}\text { PENTA, UDMA, Resin R5- } \\
\text { 62-1, T-resin, D-resin, } \\
\text { nanofiller, cetylaminehydro- } \\
\text { fluoride, and acetone }\end{array}$ & $\begin{array}{c}\text { Dentsply/Caulk, Milford, } \\
\text { DE, USA }\end{array}$ \\
\hline $\begin{array}{l}\text { Oscillating composite } \\
\text { packing instrument } \\
\text { ET } 3000^{\infty}\end{array}$ & $65 \mathrm{Ilz}$ frequency & $\begin{array}{l}\text { Brassler, USA Dental } \\
\text { instrumentation }\end{array}$ \\
\hline $\begin{array}{l}\text { Oscillating composite } \\
\text { packing instrument } \\
\text { Compothixo }\end{array}$ & $140 \mathrm{~Hz}$ frequency & Kerr, USA \\
\hline
\end{tabular}

BHT-Butylated hydroxyl toluene, PENTA phosphoric acid dipenthaerytrytole pentherylate, TEGDMA = triet-hylenglycoldimethacryate, UDMA urethane dimethacrylat

Each patient had at least three posterior teeth with proximal caries. A single operator randomly placed the three restorations in each of the selected patients. Posterior Class II cavities were prepared in the selected patients using Tungsten carbide fissure bur (carbide burs (\#245, SS White, Great White Series, Lakewood, NJ, USA) on high speed hand piece under air-water spray. A new bur was used every three cavity preparations to maintain cutting efficiency. Each patient received three prepared teeth; according to the method of composite packing, giving a total of sixty prepared teeth. In each patient the teeth were randomly allocated to be restored with composite as follows:

Group I: Twenty teeth were restored with Quixfil composite utilizing the ET3000 as packing instrument (bulk placement).

Group II: Twenty teeth were restored with Quixfil composite utilizing the Compothixo as packing instrument (bulk placement).

Group III (Control): Twenty teeth were restored with Quixfil composite using incremental placement technique (in successive increment).

Immediately before each restorative treatment, a local anesthetic was used for all patients. Class II cavity was prepared using a Tungsten carbide fissure bur \#245 at high speed with air-water spray. The cavities were prepared using a conservative cavity design. All carious tooth structure was removed to achieve the adhesive cavity design. The average faciolingual width of the cavities was 
approximately one third of the intercuspal width. Overextended cavities were not included in our study.

All restorations were placed by using rubber dam isolation. The entire cavity was etched with Conditioner 36 phosphoric acid gel for $20 \mathrm{~s}$ and thoroughly rinsed with water spray for $20 \mathrm{~s}$. Prior to application of the adhesive systems; the cavity was lightly dried with oil-free compressed air to allow penetration of the adhesive systems. Adhesive system Prime \& Bond NT was applied to the entire surface of the prepared cavity with a microbrush for $20 \mathrm{~s}$ and thereafter photocured for 10 using an LED light curing unit Blue phase, (Ivoclar Vivadent) with a power density of $1200 \mathrm{~mW} / \mathrm{cm} 2$. The intensity of the light curing unit was verified using a dental radiometer (Bluephase Meter II, Ivoclar,Vivadent). A metal retainer (TOR VM, Moscow, Russia) with a metal matrix band and a plastic wedge was used to reestablish the anatomical shape and the proximal contacts of the teeth.

Finally, Quixfil packable composite were applied to the cavities according to the method of composite packing assigned for each group, then the restoration was cured for 40 seconds. For both groups I and II the cavities were entirely filled with the packable composite starting with the proximal box to the depth of $4 \mathrm{~mm}$ bulk fill) using the oscillating packing instruments assigned for each group, then each restoration was cured for 40 seconds. The cavities were in a filled in a single-step technique without layering. For group III the cavities were filled with the packable composite starting with the proximal box using a plastic filling instrument in $2 \mathrm{~mm}$ increments. Each increment was cured for 40 seconds.

After removal of the matrix band and retainer further curing for 40 seconds was done occlusally, buccally and lingually at the proximal box area to ensure proper polymerization of the composite resin as is always practiced and indicated.

Occlusal adjustments were made at the placement visit using carbide finishing bur (Jet-Sybron, Morrisburg, ON, Canada). The quality of interproximal contacts was checked with dental floss. The restorations were finished with Sof-Lex Pop-On discs (3M ESPE, St.Paul, MN, USA) in decreasing grit size.

The clinical status of the test teeth was recorded at baseline (1 week) and 1, 3, 6, 9, 12, 15 and 18 months, the test teeth and composite restorations were rated independently using a mirror and probe. The clinical variables measured within this work were taken by two independent evaluators. In order to guarantee results homogeneity and reliability; prior to the investigation, both examiners were calibrated to $100 \%$ inter-examiner agreement on 10 patients not included in this study. In the event of disagreement, a decision was reached by consensus.

Clinical photographs of all restorations were taken with a digital camera (Nikon, Tokyo, Japan; N60/Medical lens) at the baseline and throughout the whole follow-up period (Figs.1, 2). The teeth were clinically evaluated according to modified RYGE criteria (17) (Table 2) in terms of color match, cavosurface marginal discoloration, wear anatomical form, secondary caries, marginal adaptation and surface texture.
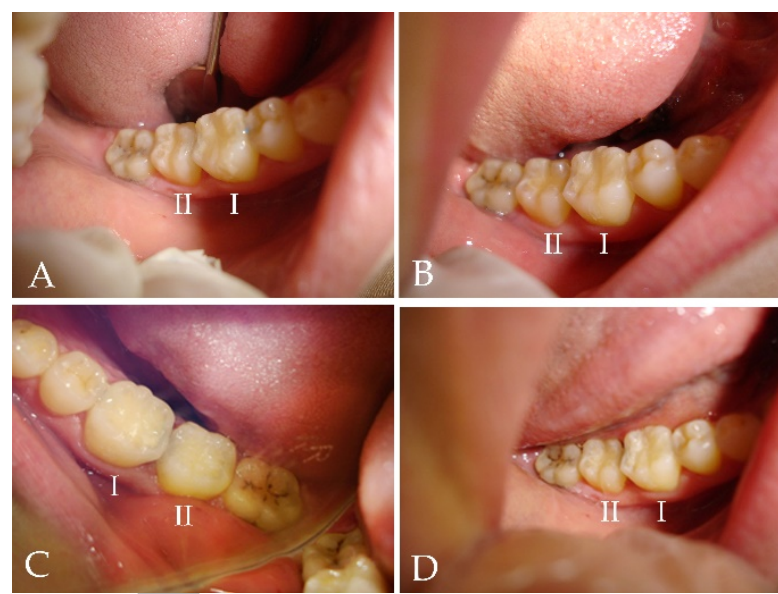

Figure 1: A) 1month post-operatively for groups I \& II, B) 6 months post-operatively for groups I \& II, C) 12 months postoperatively for groups I \& II, D) 18 months post-operatively for groups I\&II.
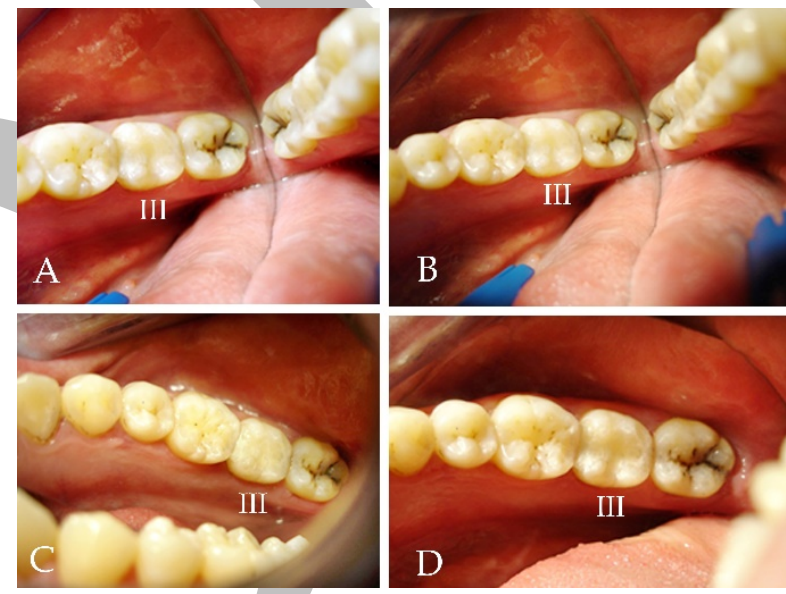

Figure (2): A) 1month post-operatively for group III, B) 6 months post-operatively for group III, C) 12 months postoperatively for group III, D) 18 months post-operatively for group III. 
Table (2): Direct clinical evaluation criteria (Modified RYGE criteria)

\begin{tabular}{|c|c|c|}
\hline Rating & Aspect & Method \\
\hline \multicolumn{3}{|c|}{ Color Match } \\
\hline Alpha (A) & $\begin{array}{l}\text { There is no mismatch in color, shade and/or translucency between } \\
\text { the restoration and the adjaccnt tooth structurc. }\end{array}$ & Visual inspection \\
\hline Bravo (B) & $\begin{array}{l}\text { There is a mismatch in color, shade and/or translucency between } \\
\text { the restoration and the adjacent tooth structure, but the mismatch } \\
\text { is within the normal range of tooth color, shade and/or } \\
\text { translucency. }\end{array}$ & Visual inspection \\
\hline Charlie (C) & $\begin{array}{l}\text { The mismatch between the restoration and the adjacent tooth } \\
\text { structure is outside the normal range of tooth color, shade and/or } \\
\text { translucency. }\end{array}$ & Visual inspection \\
\hline \multicolumn{3}{|c|}{$\begin{array}{c}\text { Cavosurface marginal discoloration } \\
\end{array}$} \\
\hline Alpha (A) & $\begin{array}{l}\text { There is no discoloration on the margin between the restoration } \\
\text { and the tooth structurc. }\end{array}$ & \\
\hline Bravo (B) & $\begin{array}{l}\text { There is discoloration anywhere on the margin between the } \\
\text { restoration and the tooth structure, but it has not penetrated along } \\
\text { the margin of the restorative material in a pulpal direction and can } \\
\text { be polished away. }\end{array}$ & Visual inspection \\
\hline Charlie (C) & $\begin{array}{l}\text { The discoloration has penetrated along the margin of the } \\
\text { restorative matcrial in a pulpal dircction. }\end{array}$ & Visual inspection \\
\hline \multicolumn{3}{|c|}{ Wear / Anatomic form } \\
\hline Alpha (A) & $\begin{array}{l}\text { The restoration is not under-contoured, that is, the restorative } \\
\text { material is not discontinuous with existing anatomic form. }\end{array}$ & Visual inspection \\
\hline Bravo (B) & $\begin{array}{l}\text { The restoration is under-contoured, that is, the restorative material } \\
\text { is discontinuous with existing anatomic form, but sufficient } \\
\text { restorative material is not missing so as to expose the dentin or } \\
\text { base. }\end{array}$ & $\begin{array}{l}\text { Visual inspection and } \\
\text { explorer. }\end{array}$ \\
\hline Charlic (C) & $\begin{array}{l}\text { Sufficient restorative material is missing so as to expose the dentin } \\
\text { or base. }\end{array}$ & Visual inspection \\
\hline \multicolumn{3}{|c|}{ Caries } \\
\hline Alpha (A) & $\begin{array}{l}\text { There is no visible evidence of a crevice along the margin into } \\
\text { which the explorer will penetrate. }\end{array}$ & $\begin{array}{l}\text { Visual inspection and } \\
\text { explorer. }\end{array}$ \\
\hline Bravo (B) & $\begin{array}{l}\text { There is visible evidence of a crevice along the margin into which } \\
\text { the explorer will penetrate. }\end{array}$ & $\begin{array}{l}\text { Visual inspection and } \\
\text { explorer. }\end{array}$ \\
\hline Charlie (C) & $\begin{array}{l}\text { There is visible evidence of a crevice along the margin into which } \\
\text { the explorer will penetrate. The dentin or base is exposed. }\end{array}$ & $\begin{array}{l}\text { Visual inspection and } \\
\text { explorer. }\end{array}$ \\
\hline Delta (D) & The restoration is fractured or missing in part or in two. & $\begin{array}{l}\text { Visual inspection and } \\
\text { explorer. }\end{array}$ \\
\hline \multicolumn{3}{|c|}{ Surface textur } \\
\hline Alpha (A) & Surfacc of restoration is smooth. & Explorer. \\
\hline Bravo (B) & $\begin{array}{l}\text { Surface of restoration I slightly rough or pitted and can be } \\
\text { refinished. }\end{array}$ & Explorer. \\
\hline Charlie (C) & $\begin{array}{l}\text { Surface is decply pitted, has irregular grooves (not related to } \\
\text { anatomy) and cannot be refinished. }\end{array}$ & Explorer. \\
\hline Delta (D) & Surface is fractured or flaking. & Explorer. \\
\hline \multicolumn{3}{|c|}{$\begin{array}{c}\text { Marginal adaptatic } \\
\end{array}$} \\
\hline Alpha (A) & Restoration closely adapted,no visible crevice & Explorer. \\
\hline & Visible crevice, explorer will penetrate & Explorer. \\
\hline Charlie (C) & Crevice in which dentin is exposed & Explorer. \\
\hline
\end{tabular}

Comparison between the study groups was performed using Freidman test at significance level 5\% $(\mathrm{P}<0.05)$. Statistical analysis was conducted using the statistical package for scientific studies (SPSS 16.0, SPSS, Inc., Chicago, IL, USA) for windows.

\section{RESULTS}

Table 3 shows the comparison among study groups in terms of color match, cavosurface marginal discoloration, wear anatomical form, secondary caries, marginal adaptation and surface texture, which was achieved by Friedman test at significance level 5\% ( $\mathrm{P}<0.05)$.

Table (3): Comparison of the three study groups according to modified RYGE criteria

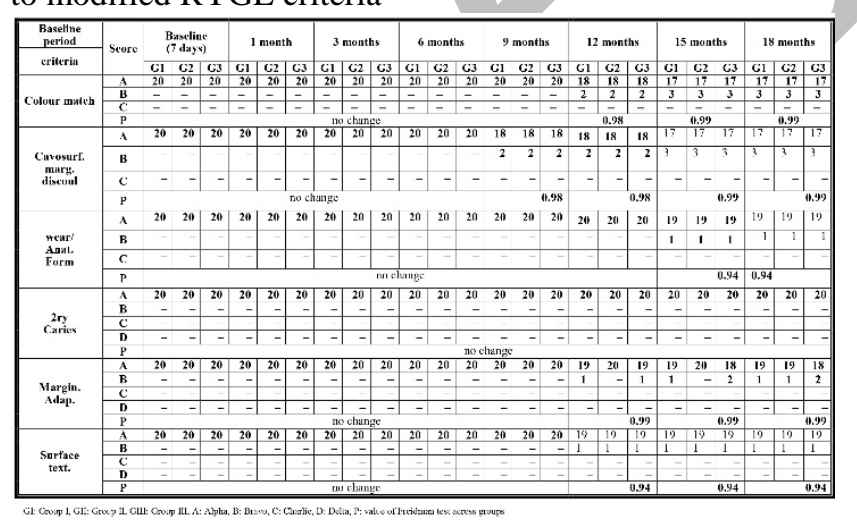

Regarding the colour match of restorations, at baseline, after one, 3, 6 and 9 months, all restored teeth in the 3 groups had score (A). At 12 months, 18 restored teeth of each of group 1, 2 and 3 had score $(\mathrm{A})$ with the remaining two restored teeth in each group having score $(\mathrm{B})(\mathrm{P}=$ 0.98). At 15 and 18 months, 17 restored teeth of each group had score (A), with the remaining restored teeth having score $(\mathrm{B})(\mathrm{P}=0.99)$. The differences in the scores of restored teeth in groups I, II and III across time was not statistically significant ( $\mathrm{P}=0.96$ for all).

The cavosurface marginal discoloration evaluation in all restored teeth in the three groups had score (A) at baseline, after one, 3 and 6 months. At 9 and 12 months, 18 restored teeth of each of group 1, 2 and 3 had score (A) with the remaining two restored teeth in each group having score $(\mathrm{B})(\mathrm{P}=0.98)$. At 15 and 18 months, 17 restored teeth of each group had score $(\mathrm{A})$, with the remaining restored teeth having score $(\mathrm{B})(\mathrm{P}=0.99)$. The differences in the scores of restored teeth in groups I, II and III across time was not statistically significant $(\mathrm{P}=0.99$ for all).

All restored teeth in the III groups had score (A) regarding the wear/ anatomic form criteria at baseline, after one, 3, 6, 9 and 12 months. At 15 and 18 months, 19 restored teeth of each of group I, II and III had score A with the remaining restored teeth in each group having score (B) $(\mathrm{P}=0.94)$. The differences in the scores of restored teeth in groups I, II and III across time was not statistically significant $(\mathrm{P}=0.99$ for all $)$.

On the other hand, none of the restored teeth in any group showed signs of recurrent caries at any follow up period.

Regarding marginal adaptation, at baseline, after one, 3 , 6 and 9 months, all restored teeth in the 3 groups had score A. At 12 months, 19 restored teeth in each of group I and III had score (A) with the remaining restored teeth in each group having score (B) and all restored teeth in group II having score $(\mathrm{A})(\mathrm{P}=0.99)$. At 15 months, 19 restored teeth in group I, all restored teeth in group II and 18 restored teeth in group III had score (A) with the remaining restored teeth in groups I and III having score $(\mathrm{B})(\mathrm{P}=0.99)$. At 18 months, 19 restored teeth of each of group I and II and 18 restored teeth in group III had score (A), with the remaining restored teeth having score $(\mathrm{B})(\mathrm{P}=0.99)$. The differences in the scores of restored teeth in groups I, II and III across time was not statistically significant in groups I, II or III $(\mathrm{P}=$ $0.98,0.83$ and 0.99 ).

All restored teeth in the 3 groups had score (A) for the surface texture criteria, at baseline, after one, 3, 6 and 9 months. At 12, 15 and 18 months, 19 restored teeth of each group had score (A) with the remaining restored teeth having score $(\mathrm{B})(\mathrm{P}=0.94)$. The differences in the scores of restored teeth in groups I, II and III across time was not statistically significant $(\mathrm{P}=0.99$ for all).

\section{DISCUSSION}

Many studies have looked at methods to improve marginal adaptation and reduce the rate of polymerization shrinkage (18). In the current study, evaluation of two oscillation packing methods for application of composite resin were investigated using both oscillating packing instruments, ET3000 (Brassler) and Compothixo (Kerr) versus the traditional incremental packing method.

The modified RYGE criteria were used for the clinical assessment of the dental restorations in our study, with the follow-up observation period up to 18 months compared to the baseline observations. This scoring system was designed to provide comprehensive evidence for clinical acceptance rather than in degrees of clinical success, this clinical assessment method resulted in ordinally structured data for the outcomes variables $\quad($ Alpha $(\mathrm{A})=$ excellent results, $\operatorname{Bravo}(\mathrm{B})$, 
Charlie $(C)=$ acceptable results, Delta $(D)=$ unacceptable and replacement of the restoration necessary). Previous studies demonstrated that an objective and reproducible clinical assessment of dental restorations can be completed using this systems (17).

All restorations evaluated in this study demonstrated acceptable clinical performance within the evaluation period based on the Alfa and Bravo ratings for clinically satisfactory restorations.

After exactly one year follow-up three out of the twenty patients (total of 9 restorations) received Bravo scores in regards to surface texture and one out ot the twenty patients (3 restorations) received Bravo score for colour match. These findings coincided with the study performed by Arhun et al (19), who evaluated Quixfil packable composite using incremental packing technique over two years followup and reported that the number of teeth showing more rough composite surface texture and color mismatch for this posterior composite started to increase after one year follow-up period. This outcome demonstrates that, inspite of using oscillation during packing of Quixfil composite resin in the current study, comparable results with the traditional incremental method were achieved and the oscillation energy from the two instuments ET 3000 and Compothixio did not affect the final scores concerning surface texture and colour match.

On the other hand, the finishing and polishing procedures, that were done after the oscillation energy was completely removed, could have partly exposed the filler particles of Quixfil packable composite. As a consequence water sorption was triggered onto the surface of the restoration, and in return this might have affected the restorations color and surface texture over time. Additionally the particle size and distribution of the inorganic filler, showed influence on the optical properties of the composite resin material in other researches (20-23).

Another point is that, Quixfil packable composite used in this study is based on UDMA matrix; this might have caused the reasonable color stability for that composite resin along the 18 months follow-up period. This outcome coincides with a study conducted by Sideridou et al (24) revealing that, UDMA-based composite resins present higher color stability than having other dimethacrylates in their resin matrix.

Apart of the oscillation procedure; good color match for Quixfil packable composite resin throughout a 3-year clinical study was reported by Celik et al (25), the authors attributed their results to the chameleon effect of Quixfil that blended into the tooth structure around the restoration especially at baseline evaluation. This was also detected in our study and may be accredited to the same reason.

As for marginal discoloration of Quixfil packable composite resin; no discoloration appeared in all groups until after 9 months. This might be related to the etching procedure of the cavities receiving Quixfil composite resin that was completed using 36\% phosphoric acid gel, allowing better retention of the restorations and decreased values of polymerization stresses at the margins, causing reduced marginal discolorations (26). Marginal staining of the restoration might have been also affected by the finish of the margins and the oral hygiene of the patient. Therefore, it could be mentioned that, oscillation energy did facilitate the adaptation and modeling of the composite resin, yet without completely eliminating the marginal defects (27).

Minor loss of anatomic form at the occlusal part as a result of wear is probably the reason for a significant AlphaBravo shift of Quixfil between baseline and 15 months in only one patient. The case demonstrating this was one of the male patients and this might be caused by the greater bite forces found in males rather than in females (28). This occurrence was also found in a study performed by Jain et al (29) who documented that, bite forces were significantly greater in males than in females ,and therefore changes in the anatomic form might be more obvious in males.

Bravo ratings for marginal adaptation in two restored teeth after 18 months, in the restorations placed with the incremental packing method were caused most probably by marginal opening due to adhesive failures during clinical service (30). The oscillation energy applied from the two other packing instruments enhanced the sealing ability of Quixfil in the other groups, as it temporarily increased the flowability of the packable composite, hence facilitated its placement and adaptation, therefore better results were achieved.

In our study class II restorations were evaluated and larger volumes of composite resin were used. This large volume could have resulted in an increase in residual internal stresses in the polymerized composite at the composite-tooth interface, exceeding the strength of the bond between composite and enamel, although incrementally placed, leading to failure at marginal of the restoration over time. This was also perceived in other clinical studies, where higher marginal failure rates for incrementally placed posterior composite restorations, especially in Class II defects, were noted over time (31, 32).

An important finding was that no recurrent caries was observed in all restorations throughout the whole followup period. Possible explanations for this good performance and the Alpha scores regarding recurrent caries in our study may be a) the relatively short evaluation period consistent with findings of many authors, who did not observe significant changes in short-time periods (33) and b) the enhanced sealing ability of Quixfil packable composite resin due to implementation of oscillation energy, especially at the margins of the restorations, which was noticeable in this study.

In a survey of a 4-year clinical assessment of Quixfil packable composite by Manhart et al (28) same results were obtained as this study, and this revealed that, good clinical results with predominantly Alfa scores for Quixfil composite resin can be achieved by incremental placement technique as well as with oscillation placement methods.

It should be also highlighted that when Beck et al (34) analyzed the survival of posterior composite restorations followed-up within 19 years, it was concluded that the failure rate of composite restorations in posterior teeth increases with longer observation periods. Hence the possibility of having Alpha scores would have been less found if longer follow up periods where done.

The current study shows that the results of oscillation packing are comparable to those of the traditional incremental technique. Therefore, the null hypothesis, that there would be no difference in the clinical behavior of the 
packable composite resin after using the oscillation packing method, can be accepted.

\section{CONCLUSION}

In light of this information, it was concluded that, the clinical assessment of Quixfil packable posterior composite restorations for 18 months for all packing techniques, showed good clinical results with predominating Alpha scores. With the limitations of this study, the oscillation energy with packing techniques did not affect the sealing ability of the material.

\section{CONFLICT OF INTEREST}

The authors declare that they have no conflicts of interest.

\section{REFERENCES}

1.Santhosh L, Bashetty K, Nadig G. The influence of different composite placement techniques on microleakage in preparations with high C-factor: An in vitro study. J Conserv Dent. 2008; 11: 112-6.

2.Lyons K. Direct placement restorative materials for use in posterior teeth: the current options. N Z Dent J. 2003; 99: 10-5.

3.Ayub KV, Santos GC Jr, Rizkalla AS, Bohay R, Pegoraro LF, Rubo JH, et al. Effect of preheating on microhardness and viscosity of 4 resin composites. J Can Dent Assoc. 2014; 80: e12.

4. Kapoor N, Bahuguna N, Anand S. Influence of composite insertion technique on gap formation. J Conserv Dent. 2016; 19: 77-81.

5. Yeolekar TS, Chowdhary NR, Mukunda KS, Kiran NK. Evaluation of microleakage and marginal ridge fracture resistance of primary molars restored with three restorative materials: A comparative in vitro study. Int J Clin Pediatr Dent. 2015; 8: 108-13.

6.Chi HH. A Posterior Composite Case Utilizing the Incremental and Stratified Layering Technique. Oper Dent. 2006; 31: 512-6.

7.Braga RR, Ballester RY, Ferrecane JL. Factors involved in the development of polymerization shrinkage stress in resincomposites: a systematic review. Dent Mater. 2005; 21: 96270.

8. Papadogiannis Y, Lakes RS, Palaghias G, HelvatjogluAntoniades M, Papadogiannisc D. Fatigue of packable dental composites. Dent Mater. 2007; 23: 235-42.

9. AL-Azzawi HJ, AL-Hyali NA, Al-Dabbagh FJM. Microleakage of class II packable resin composite lined with flowable composite and resin modified glass 6 ionomer cement: An in vitro study. JBCD. 2102; 24: 6-10.

10. Her SC, Lin CS. Vibration analysis of composite laminate excited by piezoelectric actuators. Sensors (Basel). 2013; 13: 2997-3013.

11. Trujillo M, Newman SM, Stansbury JW. Use of near-IR to monitor the influence of external heating on dental composite photo polymerization. Dent Mater. 2004; 20: 766-77.

12. Ozcan M, Mese A. Effect of Ultrasonic Versus Manual Cementation on the Fracture Strength of Resin Composite Laminates. Oper Dent. 2009; 34: 437-42.

13. Puckett AD, Fitchie JG, Kirk PC, Gamblin J. Direct composite restorative materials. Dent Clin North Am. 2007; 51: 659-75.
14. Didem A, Gözde Y, Nurhan Ö. Comparative Mechanical Properties of Bulk-Fill Resins. Open J Compos Mater 2014; 4: 117-21.

15. Palaniappan S, Elsen L, Lijnen I, Peumans M. Threeyear randomized clinical trial to evaluate the clinical performance, quantitative and qualitative wear patterns of hybrid composite restorations. Clin Oral Invest. 2010; 14 : 441-58.

16. Celik C, Arhun N, Yamanel K. Clinical evaluation of resin-based composites in posterior restorations: 12month results. Eur J Dent. 2010; 4: 57-65.

17. Ryge G, Jendresen MD, Glantz PO, Mjör IA. Standardization of clinical investigators for studies of restorative materials. Swed Dent J. 1981; 5: 235-9.

18. Liu Y, Tjaderhane L, Breschi L, Mazzoni A, Li N, Mao J, et al. Limitations in bonding to dentin and experimental strategies to prevent bond degradation. J Dent Res. 2011; 90: 953-68.

19. Arhun N, Celik C, Yamanel K. Clinical evaluation of resin-based composites in posterior restorations: two-year results. Oper Dent. 2010; 35: 397-404.

20. Dos Santos GB, Monte Alto RV, Sampaio Filho HR, Da Silva EM, Fellows CE. Light transmission on dental resin composites. Dent Mater. 2008; 24: 571-6.

21. Lee YK. Influence of filler on the difference between the transmitted and reflect colors of experimental resin composites. Dent Mater. 2008; 24: 1243-7.

22. Lim YK, Lee YK, Lim BS, Rhee SH, Yang HC. Influence of filler distribution on the color parameters of experimental resin composites. Dent Mater. 2008; 24: 6773.

23. Sideridou I, Tserki V, Papanastasiou G. Study of water sorption, solubility and modulus of elasticity of light-cured dimethacrylate-based dental resins. Biomaterials. 2003; 24:655-65.

24. Sideridou ID, Achilias DS. Elution study of unreacted BisGMA, TEGDMA, UDMA, and Bis-EMA from light-cured dental resins and resin composites using HPLC. J Biomed Mater Res B Appl Biomater. 2005; 74: 617-26.

25. Celik C, Arhun N, Yamanel K. Clinical evaluation of resinbased composites in posterior restorations: a 3-year study. Med Princ Pract. 2014; 23: 453-9.

26. Muhamad AH, Azzaldeen A, Abdulgani M. Esthetics of Class IV Restorations with Composite Resins. J Dent Med Sci. 2016; 15: 61-6.

27. Iovan G, Stoleriu S, Moldovanu A, Morogai S, Andrian S. SEM study of the interface between the cavity wall and composite resin in cavities filled using vibration. IJMD. 2011; 1: 254-8.

28. Manhart J, Chen HY, Hickel R. Clinical evaluation of the posterior composite Quixfil in class I and II cavities: 4year follow-up of a randomized controlled trial. J Adhes Dent. 2010; 12: 237-43.

29. Jain V, Mathur VP, Pillai RS, Kalra S. A preliminary study to find out maximum occlusal bite force in Indian individuals. Indian J Dent Res. 2014; 25: 325-30.

30. Carvalho RM, Manso AP, Geraldeli S, Tay FR, Pashley DH. Durability of bonds and clinical success of adhesive restorations. Dent Mater. 2012; 28: 72-86.

31. Bohaty BS, Ye Q, Misra A, Sene F, Spencer P. Posterior composite restoration update: focus influencing form and function. Clin Cosmet Investig Dent. 2013; 5: 33-42.

32. Opdam NJM, van de Sande FH, Bronkhorst E, Cenci MS, Bottenberg P, Pallesen U, et al. Longevity of 
Posterior Composite Restorations: A Systematic Review and Meta-analysis. J Dent Res. 2014; 93: 943-9.

33. Fagundes TC, Barata TJ, Bresciani E, Cefaly DF, Jorge MF, Navarro MF. Clinical evaluation of two packable posterior composites: 2-year follow-up. Clin Oral Investig. 2006; 10: 197-203.

34. Beck F, Lettner S, Graf A, Bitriol B, Dumitrescu N, Bauer $\mathrm{P}$, et al. Survival of direct resin restorations in posterior teeth within a 19-year period (1996-2015): A metaanalysis of prospective studies. Dent Mater. 2015; 31: 95885.

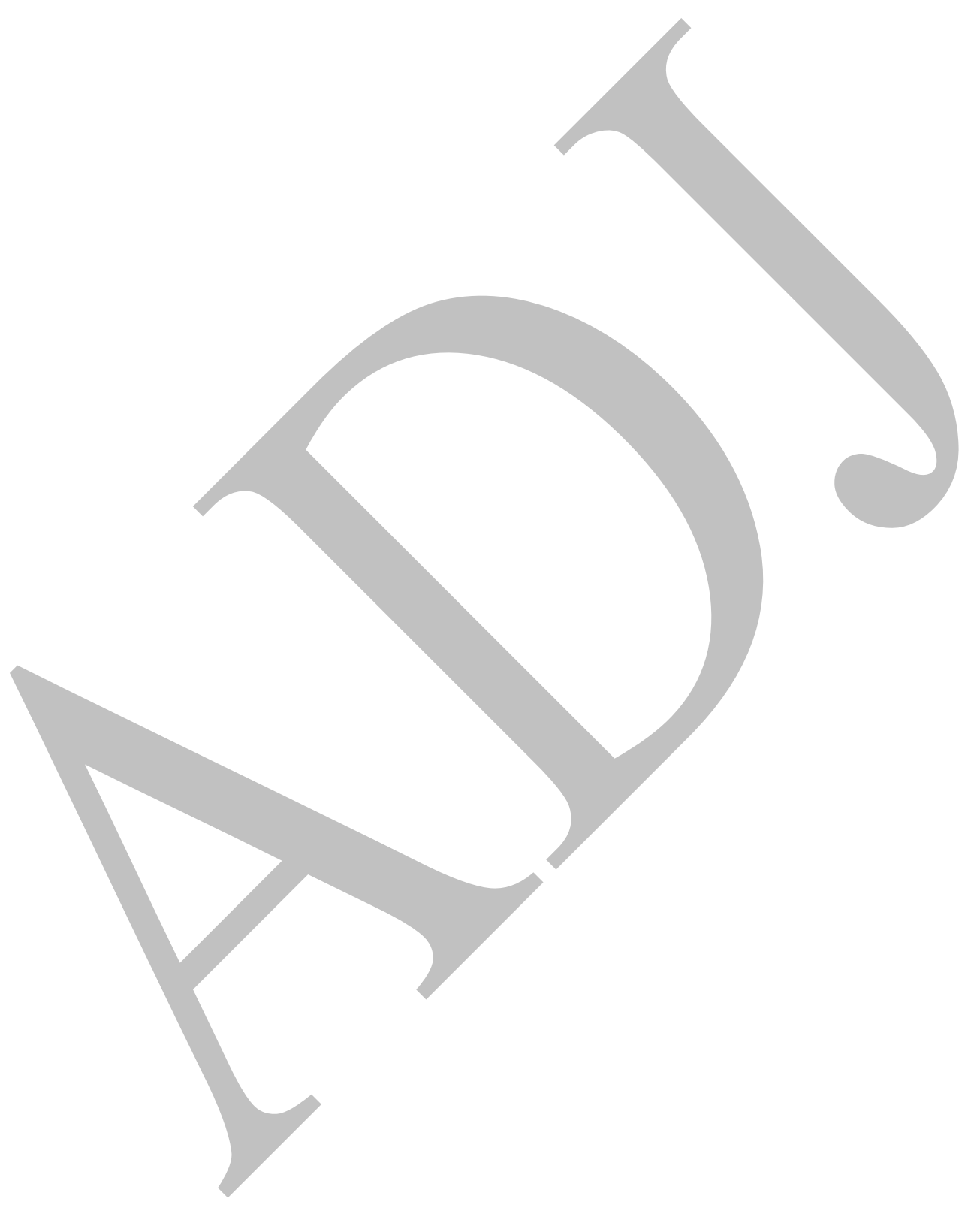

